\title{
Association of conditioned stimuli during serial conditioning by pigeons
}

\author{
EDWARD A. WASSERMAN, DONALD L. CARR, and JAMES D. DEICH \\ The University of Iowa, Iowa City, Iowa 52242
}

\begin{abstract}
CS2-CS1-US autoshaping was given to hungry pigeons and evidence of CS2-CS1 association was sought. Pigeons pecked that key of a two-key compound CS2 located where the upcoming CS1 key light was to occur. Such CS2-CS1 association was: (1) quickly acquired, (2) quite durable, and (3) stronger with simultaneous than with successive discrimination tasks.
\end{abstract}

When a series of nonoverlapping stimuli is presented prior to reinforcer delivery (for example, CS2, CS1, US), a number of associative connections between the stimuli may be formed (see Rudenko, 1974). For instance, associations between each conditioned stimulus and the unconditioned stimulus might be elaborated-CS1-US and CS2-US. Additionally, the possibility exists that a direct associative connection between the conditioned stimuli may be laid-CS2-CS1. Such a possibility would clearly be in keeping with the previously reported phenomena of sensory preconditioning (Razran, 1971; Seidel, 1959; Thompson, 1972) and higher-order conditioning (Mackintosh, 1974; Rescorla, 1973). However, within the context of serial conditioning, it has been a difficult analytical matter to ascribe responding during CS2 to CS2-CS1 or to CS2-US conditioned connections (see Wickens, 1973).

The present study reports the results of two experiments that used a new procedure aimed at revealing the involvement of CS-CS connections in serial conditioning. Briefly, this procedure exploited the fact that the pigeon's autoshaped keypecking is directed primarily toward only one localized stimulus even though more than one stimulus may be presented at the moment (Wasserman, 1974; Wasserman \& Anderson, 1974; Wasserman \& McCracken, 1974). Using such multiple stimulus compounds as CS2, it was then possible to determine by the pigeon's choice of pecking keys whether the subject was anticipating the location of the upcoming CS1. To the degree that the subjects anticipated correctly, discriminative responding could reflect the elaboration of CS2-

This research was supported by grants from the National Institute of Mental Health (MH-24482) and the National Science Foundation (BNS 75-15905) and by funds from the Graduate College, The University of Iowa. The authors gratefully thank K. R. Nelson for his technical help as well as A. Dickinson, N. J. Mackintosh, and C. A. Riley for their constructive comments. Requests for reprints should be sent to E. A. Wasserman, Department of Psychology, The University of Iowa, Iowa City, Iowa 52242.
CS1 associations, quite apart from the possibility that CS2-US associations had also been formed.

In order to extend the generality of the behavioral results and to determine the extent to which these results were influenced by well-established variables, simultaneous (Experiment 1) and successive (Experiment 2) discrimination problems were investigated. Before describing the details of each of these investigations, the general experimental methods will first be outlined.

\section{GENERAL METHOD}

\section{Subjects}

The subjects were adult domestic pigeons of both sexes maintained at $80 \%$ of their free-feeding weights by postsession feedings of mixed grain. Throughout the period of study, they had free access to grit and fresh water.

\section{Apparatus}

Two standard Lehigh Valley Electronics three-key cubicles were employed, but the center key was taped over and never used. The left and right keys could be activated when contact exceeded $15 \mathrm{~g}(.15 \mathrm{~N})$, and they could be transilluminated white, green, or red when $28-\mathrm{V}$ dc was applied to miniature incandescent bulbs (ESB 24). Directly above the center key was the houselight, which provided general chamber illumination during the experimental sessions (see Wasserman, 1973) when 6.3-V ac was applied to an encased bulb (GE 44). Directly below the center key was the hopper opening through which grain reinforcers were made available when the hopper was elevated and illuminated. Extraneous sounds produced by the scheduling circuitry and recording equipment located in an adjoining room were masked by white noise supplied to a small loudspeaker in the experimental room and by ventilating fans attached to each of the conditioning cubicles.

\section{Procedure}

In both experiments, experimentally naive and previously autoshaped subjects were studied. The pretrained subjects had earlier been autoshaped to keypeck. The experimentally naive subjects were trained to eat from the intermittently activated grain hopper on the day before experimental training.

During experimental training, the $\mathbf{4 0}$ daily trials involved the nonoverlapping presentation of CS2, CS1, and US with the corresponding stimulus durations being 10,10 , and $2.50 \mathrm{sec}$. The trials were separated by 60 -sec intertrial intervals (ITIs) during which the response keys were dark. CS2 always entailed the illumination of both the left and right pecking keys; CS1 always 
entailed the single illumination of the left or the right key on a random half of the trials. The relationships between the compound CS2 stimuli and the single CS1 key light are shown in Table 1 for Experiments 1 and 2. In the simultaneous discrimination problem of Experiment 1, on any trial CS2 involved green illumination on one key and red illumination on the other, and the position of the green and red lights varied from one trial to the next. Which key would next be illuminated with the white CS1 light was determined by the location of one particular color of key light during the prior CS2. In the successive discrimination problem of Experiment 2, on any trial CS2 involved the illumination of both keys with the same color of light and that key color varied from one trial to the next. Which key would next be white-illuminated as CS1 depended on which color had illuminated both keys during the prior CS2.

The relative frequency of pecking the two keys during CS2 served as the basis for inferring that the pigeons had associated CS2 and CS1. Specifically, if the pigeons associated the two types of CS2 and CS1 stimuli, then during CS2 they might peck the particular key that was to be illuminated during CS1.

\section{EXPERIMENT 1}

The first experiment sought to obtain evidence of CS-CS association during serial conditioning under highly favorable conditions. Therefore, the simultaneous discrimination problem was utilized, as prior work has generally found this procedure to be superior to a comparable successive discrimination problem (Sutherland \& Mackintosh, 1971).

\section{Method \\ Four experimentally naive pigeons and eight others that had earlier been conditioned with related procedures to peck green and red key lights were exposed for 10 days to the procedure shown in the top half of Table 1. A random half of the daily trials involved as CS2 the simultaneous illumination of the left and right keys with Color 1 and Color 2, respectively; on the remaining trials, the left key displayed Color 2 and the right key displayed Color 1. Immediately following CS2 offset, white illumination of the same key as was lighted with Color 1 occurred as CS1. For half of the naive and half of the pretrained birds, Color 1 was green and Color 2 was red; the opposite assign- ments were made for the remaining pigeons. Food presentation occurred on all trials immediately following CS1 offset.}

\section{Results and Discussion}

Both the naive and pretrained birds quickly came to peck at the green and red key lights constituting CS2, and at the white CS1 light on whichever key it appeared. Figure 1 illustrates the course of selective responding to Color 1 and Color 2 during CS2 over the 10 days of training for all birds. As in related autoshaping experiments (e.g., Wasserman, Franklin, \& Hearst, 1974), a tracking ratio was computed according to the formula: (Color 1 pecks during CS2) $\div$ (total CS2 pecks) $\times 100$. A score of 50 thus denotes indiscriminate pecking at the green and red key lights, whereas a score of 100 indicates exclusive responding to that color of key light during CS2 that immediately preceded presentation of the white CS1 stimulus on the same key. As training progressed, the median tracking ratio of the 12
Table 1

Trial Sequence and Median Rate of Pecking (Keypecks per Minute) the Left and Right Keys During CS1 and CS2 Uver Days 9 and 10 of Training for All Subjects

\begin{tabular}{|c|c|c|c|c|}
\hline \multirow[b]{2}{*}{ Trial Sequence } & \multicolumn{2}{|c|}{ Trial Type 1} & \multicolumn{2}{|c|}{ Trial Type 2} \\
\hline & Left & Right & Left & Right \\
\hline & \multicolumn{4}{|c|}{ Simultaneous Discrimination Problem } \\
\hline ITI for $60 \mathrm{sec}$ & Dark & Dark & Dark & Dark \\
\hline $\mathrm{CS} 2$ for $10 \mathrm{sec}$ & Color 1 & Color 2 & Color 2 & Color 1 \\
\hline Peck Rate & 15.38 & 0.30 & 0.30 & 25.95 \\
\hline CS1 for $10 \mathrm{sec}$ & White & Dark & Dark & White \\
\hline Peck Rate & 67.43 & 0.00 & 0.00 & 58.35 \\
\hline \multirow[t]{2}{*}{ Grain for $2.5 \mathrm{sec}$} & Dark & Dark & Dark & Dark \\
\hline & \multicolumn{4}{|c|}{ Successive Discrimination Problem } \\
\hline ITI for $60 \mathrm{sec}$ & Dark & Dark & Dark & Dark \\
\hline $\mathrm{CS} 2$ for $10 \mathrm{sec}$ & Color 1 & Color 1 & Color 2 & Color 2 \\
\hline Peck Rate & 15.38 & 4.80 & 2.85 & 14.10 \\
\hline CS1 for $10 \mathrm{sec}$ & White & Dark & Dark & White \\
\hline Peck Rate & 30.90 & 0.00 & 0.00 & 34.20 \\
\hline Grain for $2.5 \mathrm{sec}$ & Dark & Dark & Dark & Dark \\
\hline
\end{tabular}

pigeons quickly increased and reached 90 on Day 7 of training. The median rate of pecking the left and right keys during CS2 and CS1 over Days 9 and 10 of training is shown in Table 1 . Not only did the pigeons peck at Color 1 more than at Color 2 regardless of its location, but also they generally pecked during CS1 at a higher rate than during CS2 (see Newlin \& LoLordo, 1976; Ricci, 1973). On these 2 days of training, the median tracking ratio was 89.91 (range: 58.91 to 100.00 ).

The results of the simultaneous discrimination experiment thus establsh that pigeons do learn to peck that element of a compound of differently colored stimuli which both precedes and locates the upcoming presentation of another signal paired with food delivery. Such selective responding is consistent with an interpretation stressing the learning of associations between conditioned stimuli such as the illuminated keys used here. However, in order to be sure that these results were reliable and that the selective responding evidenced during CS2 was not totally dependent upon the simultaneous presence of differently colored lights at the time that the choice of pecking keys was made, a successive discrimination problem was devised and used in a second experiment with 12 different pigeons.

\section{EXPERIMENT 2}

\section{Method}

All of the procedural details and subject characteristics were the same as in the first experiment, except for the compound stimuli constituting CS2. The bottom half of Table 1 indicates that here, when CS2 involved Color 1 on both keys, the white CS1 followed on the left key; when CS2 entailed Color 2 on both keys, the white CS1 followed on the right key. To see whether subjects discriminatively pecked the key during CS2 that was later to be white-illuminated during CS1, we redefined the tracking 
ratio apropos to this procedure: (left pecks during Color $1+$ right pecks during Color 2 in CS2) $\div$ (total CS2 pecks) $\times 100$.

\section{Results and Discussion}

Figure 1 shows that the pigeons did indeed learn to peck the key during CS2 that would next be illuminated during CS1. Tracking ratios increased to a median near 75 by Day 4 of training. The median rate of pecking the left and right keys during CS1 and CS2 over Days 9 and 10 is shown in Table 1 . Discriminative performance was evidenced on both types of CS2 trial, as was the generally higher rate of pecking to CS1 than CS2. During these 2 days of training, the median tracking ratio was 73.01 (range: 50.13 to 90.97 ). Therefore, association of compound conditioned stimuli with a spatially shifting subsequent one occurs even if the differently colored compound stimuli are successively, rather than simultaneously, presented.

As is often the case in more conventional discrimination learning paradigms, the discriminative performance of simultaneous discrimination subjects markedly exceeded that of successive discrimination subjects over Days 9 and 10, Mann-Whitney $U=$ $23.5, \mathrm{p}<.01$, one-tailed. It should be noted, however, that over Days 9 and 10 of training, all 24 pigeons in both experiments evidenced tracking ratios in excess of a chance performance level of 50 , binomial $\mathrm{p}<.001$, two-tailed.

Yet another, possibly more conservative, way of assessing the statistical significance of the present results involves "subproblem" analysis. For each type of CS2 trial, either the left or the right key was designated the "correct" one. One point was assigned if a given bird pecked the left key more than the right on Type 1 trials and another point was assigned if it pecked the right key more than the left on Type 2 trials, thus permitting pigeons to receive a maximum of 2 points if they pecked "correctly" on Type 1 and Type 2 trials. Here, chance performance would be indicated by a score of 1 point. Over Days 9 and 10 in the simultaneous discrimination experiment, nine birds received 2 points, three birds received 1 point, and none received 0 points; $\chi^{2}(2)=16.33, \mathrm{p}<.001$. Over Days 9 and 10 in the successive discrimination experiment, eight pigeons received 2 points, four pigeons received 1 point, and none received 0 points, $\chi^{2}(2)=12.00, p<.01$.

Although the results of the experimentally naive subjects were quite similar to those of birds given preliminary autoshaping, greater detail as to the acquisition of responding to CS2 and CS1 seems warranted. Table 2 depicts the acquisition of conditioned stimulus control during the 10 days of training for each of the eight naive pigeons. It can be seen that, with the exception of Bird 171, differential responding during CS2 generally arose within 1 week of training after a phase of indiscriminate pecking at both left

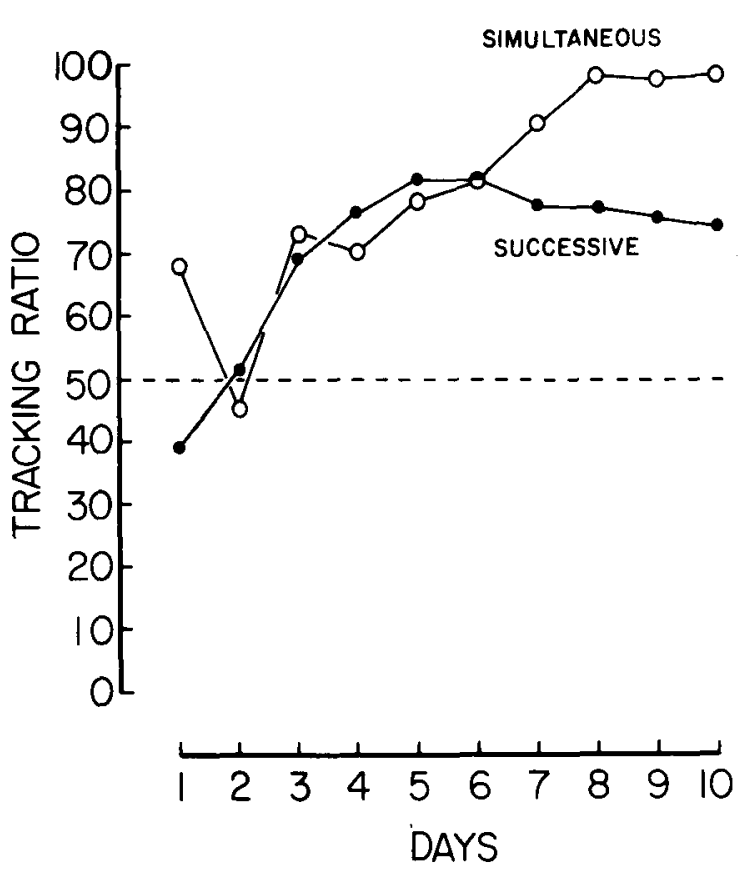

Figure 1. Median tracking ratios of subjects in the simultaneous (Experiment 1) and successive (Experiment 2) discrimination experiments over the first 10 days of experimental training. Chance tracking performance of $\mathbf{5 0}$ is also indicated.

and right keys. Thus, these individual subject data are highly consistent with the group data presented in Table 1 and Figure 1. Somewhat less consistent, perhaps, were the absolute levels of responding to CS1 and CS2 over Days 9 and 10 . While all 4 successive discrimination birds responded more to CS1 than to CS2, this was true of only 1 of the 4 simultaneous discrimination birds: Overall, 8 out of 12 birds in each experiment keypecked more to CS1 than to CS2 on Days 9 and 10.

Finally, in order to assess the durability of the CS2-CS1 conditioning effects, the eight naive birds were trained for an additional 10 days and tracking ratios were computed over Days 11 to 20 of training. For the simultaneous discrimination birds, 187, 188, 189 , and 190 , tracking ratios were $77.12,95.80$, 96.23 , and 91.81 , respectively; for the successive discrimination birds, $171,143,157$, and 170 , tracking ratios were $69.23,75.92,91.01$, and 62.61 , respectively. The CS2-CS1 conditioning effects were, therefore, highly reliable and durable.

\section{GENERAL DISCUSSION}

Taken together, the results of the present pair of experiments support the proposition that conditioning with the sequence CS2-CS1-US leads to the elaboration of a CS2-CS1 associative connection. Pigeons pecked that element of a compound CS2 stimulus which was located at the same place where an upcom- 
Table 2

Rate of Pecking (Keypecks per Minute) the Left and Right Keys During CS1 and CS2 in Successive 2-Day Blocks Over Days 1 to 10 by the Eight Naive Pigeons

\begin{tabular}{|c|c|c|c|c|c|c|c|c|c|}
\hline \multirow[b]{3}{*}{ Subject } & \multirow{3}{*}{$\begin{array}{l}\text { 2-Day } \\
\text { Block }\end{array}$} & \multicolumn{4}{|c|}{ CS2 Trials } & \multicolumn{4}{|c|}{ CS1 Trials } \\
\hline & & \multicolumn{2}{|c|}{ Type 1} & \multicolumn{2}{|c|}{ Type 2} & \multicolumn{2}{|c|}{ Type 1} & \multicolumn{2}{|c|}{ Type 2} \\
\hline & & Left & Right & Left & Right & Left & Right & Left & Right \\
\hline & \multicolumn{9}{|c|}{ Simultaneous Discrimination Problem } \\
\hline $187(\mathrm{R})$ & $\begin{array}{l}1 \\
2 \\
3 \\
4 \\
5\end{array}$ & $\begin{array}{r}2.40 \\
1.50 \\
47.70 \\
60.00 \\
73.95\end{array}$ & $\begin{array}{l}3.45 \\
1.05 \\
6.30 \\
1.20 \\
0.90\end{array}$ & $\begin{array}{l}3.00 \\
0.45 \\
8.25 \\
5.70 \\
5.70\end{array}$ & $\begin{array}{r}3.75 \\
0.90 \\
53.10 \\
61.20 \\
75.60\end{array}$ & $\begin{array}{r}0.90 \\
6.15 \\
75.60 \\
69.00 \\
69.75\end{array}$ & $\begin{array}{l}0.00 \\
0.15 \\
0.30 \\
0.00 \\
0.00\end{array}$ & $\begin{array}{l}0.00 \\
0.00 \\
0.15 \\
0.00 \\
0.00\end{array}$ & $\begin{array}{r}4.64 \\
6.60 \\
72.15 \\
73.65 \\
74.40\end{array}$ \\
\hline $188(\mathrm{R})$ & $\begin{array}{l}1 \\
2 \\
3 \\
4 \\
5\end{array}$ & $\begin{array}{l}2.55 \\
8.40 \\
7.05 \\
8.40 \\
7.50\end{array}$ & $\begin{array}{l}2.55 \\
0.00 \\
0.30 \\
0.00 \\
0.30\end{array}$ & $\begin{array}{l}3.30 \\
0.75 \\
0.00 \\
0.00 \\
0.00\end{array}$ & $\begin{array}{r}2.10 \\
6.60 \\
7.20 \\
8.25 \\
17.10\end{array}$ & $\begin{array}{r}4.05 \\
21.15 \\
31.50 \\
35.40 \\
31.05\end{array}$ & $\begin{array}{l}0.00 \\
0.00 \\
0.00 \\
0.00 \\
0.00\end{array}$ & $\begin{array}{l}0.00 \\
0.00 \\
0.00 \\
0.00 \\
0.00\end{array}$ & $\begin{array}{r}8.25 \\
18.45 \\
36.60 \\
44.85 \\
47.10\end{array}$ \\
\hline $189(G)$ & $\begin{array}{l}1 \\
2 \\
3 \\
4 \\
5\end{array}$ & $\begin{array}{r}0.00 \\
2.70 \\
41.25 \\
35.70 \\
34.50\end{array}$ & $\begin{array}{l}0.00 \\
6.90 \\
0.00 \\
0.00 \\
0.00\end{array}$ & $\begin{array}{r}0.00 \\
12.00 \\
2.85 \\
2.70 \\
0.00\end{array}$ & $\begin{array}{r}0.15 \\
0.75 \\
32.25 \\
46.95 \\
44.25\end{array}$ & $\begin{array}{r}0.15 \\
20.40 \\
39.75 \\
43.20 \\
20.40\end{array}$ & $\begin{array}{l}0.00 \\
0.15 \\
0.00 \\
0.00 \\
0.00\end{array}$ & $\begin{array}{l}0.00 \\
0.60 \\
0.00 \\
0.15 \\
0.00\end{array}$ & $\begin{array}{r}0.75 \\
19.50 \\
43.65 \\
35.10 \\
15.30\end{array}$ \\
\hline $190(\mathrm{G})$ & $\begin{array}{l}1 \\
2 \\
3 \\
4 \\
5\end{array}$ & $\begin{array}{r}6.15 \\
4.95 \\
6.90 \\
52.20 \\
60.90\end{array}$ & $\begin{array}{r}2.85 \\
22.65 \\
36.30 \\
1.20 \\
3.00\end{array}$ & $\begin{array}{r}1.50 \\
21.60 \\
68.10 \\
21.45 \\
3.15\end{array}$ & $\begin{array}{r}5.25 \\
0.15 \\
0.00 \\
31.20 \\
60.90\end{array}$ & $\begin{array}{r}7.50 \\
8.55 \\
46.65 \\
59.70 \\
52.35\end{array}$ & $\begin{array}{l}0.15 \\
1.50 \\
1.20 \\
0.00 \\
0.15\end{array}$ & $\begin{array}{l}0.00 \\
1.05 \\
1.35 \\
0.15 \\
0.00\end{array}$ & $\begin{array}{r}9.45 \\
8.40 \\
45.15 \\
54.45 \\
57.15\end{array}$ \\
\hline \multicolumn{10}{|c|}{ Successive Discrimination Problem } \\
\hline $171(\mathrm{G})$ & $\begin{array}{l}1 \\
2 \\
3 \\
4 \\
5\end{array}$ & $\begin{array}{l}3.90 \\
1.50 \\
0.15 \\
0.00 \\
0.00\end{array}$ & $\begin{array}{r}13.20 \\
2.40 \\
1.05 \\
0.00 \\
0.60\end{array}$ & $\begin{array}{l}6.60 \\
5.70 \\
2.55 \\
0.00 \\
0.90\end{array}$ & $\begin{array}{r}5.85 \\
10.50 \\
3.60 \\
1.05 \\
1.80\end{array}$ & $\begin{array}{l}21.30 \\
18.45 \\
36.90 \\
38.40 \\
30.15\end{array}$ & $\begin{array}{l}0.30 \\
0.00 \\
0.00 \\
0.00 \\
0.00\end{array}$ & $\begin{array}{l}0.45 \\
0.00 \\
0.00 \\
0.00 \\
0.00\end{array}$ & $\begin{array}{l}39.00 \\
51.45 \\
44.85 \\
33.90 \\
38.40\end{array}$ \\
\hline $143(\mathrm{G})$ & $\begin{array}{l}1 \\
2 \\
3 \\
4 \\
5\end{array}$ & $\begin{array}{r}9.60 \\
21.30 \\
19.65 \\
8.10 \\
9.60\end{array}$ & $\begin{array}{r}10.95 \\
5.55 \\
2.10 \\
7.35 \\
5.55\end{array}$ & $\begin{array}{l}9.30 \\
7.35 \\
7.50 \\
1.65 \\
2.40\end{array}$ & $\begin{array}{r}10.80 \\
6.90 \\
14.40 \\
15.00 \\
18.00\end{array}$ & $\begin{array}{l}42.45 \\
74.10 \\
74.10 \\
84.00 \\
84.60\end{array}$ & $\begin{array}{l}0.30 \\
0.00 \\
0.00 \\
0.15 \\
0.15\end{array}$ & $\begin{array}{l}0.45 \\
0.15 \\
0.45 \\
0.00 \\
0.00\end{array}$ & $\begin{array}{l}40.05 \\
69.45 \\
60.90 \\
78.60 \\
84.90\end{array}$ \\
\hline $157(\mathrm{R})$ & $\begin{array}{l}1 \\
2 \\
3 \\
4 \\
5\end{array}$ & $\begin{array}{l}0.60 \\
4.20 \\
3.15 \\
6.30 \\
6.60\end{array}$ & $\begin{array}{l}1.05 \\
3.00 \\
0.15 \\
1.05 \\
0.15\end{array}$ & $\begin{array}{l}1.05 \\
3.45 \\
2.55 \\
1.80 \\
2.70\end{array}$ & $\begin{array}{r}2.25 \\
7.50 \\
12.75 \\
7.50 \\
11.70\end{array}$ & $\begin{array}{r}2.25 \\
20.40 \\
29.55 \\
30.30 \\
29.85\end{array}$ & $\begin{array}{l}0.00 \\
0.75 \\
0.15 \\
0.30 \\
0.00\end{array}$ & $\begin{array}{l}0.00 \\
0.00 \\
0.00 \\
0.00 \\
0.00\end{array}$ & $\begin{array}{r}6.75 \\
27.60 \\
24.45 \\
18.30 \\
13.80\end{array}$ \\
\hline $170(\mathrm{R})$ & $\begin{array}{l}1 \\
2 \\
3 \\
4 \\
5\end{array}$ & $\begin{array}{l}16.35 \\
54.60 \\
47.55 \\
28.20 \\
24.60\end{array}$ & $\begin{array}{r}9.90 \\
13.50 \\
6.75 \\
5.25 \\
14.85\end{array}$ & $\begin{array}{l}9.45 \\
8.55 \\
3.30 \\
2.40 \\
3.00\end{array}$ & $\begin{array}{r}4.65 \\
7.35 \\
3.00 \\
5.55 \\
11.10\end{array}$ & $\begin{array}{l}32.85 \\
79.05 \\
79.35 \\
79.80 \\
81.15\end{array}$ & $\begin{array}{l}0.45 \\
0.60 \\
0.45 \\
0.00 \\
0.30\end{array}$ & $\begin{array}{l}0.30 \\
0.00 \\
0.00 \\
0.00 \\
0.00\end{array}$ & $\begin{array}{l}29.10 \\
67.20 \\
81.15 \\
87.45 \\
87.75\end{array}$ \\
\hline
\end{tabular}

Note-The letter in parentheses next to the subject number indicates the color of the left key (R-red, G-green) during CS2 trials of Type 1 for each individual subject.

ing CS1 stimulus was to occur. Thus, the measure of CS2-CS1 association here involved the relative amount of keypecking to the respective elements of CS2. Work by Rudenko (1974) also found evidence of CS2-CS1 associations. However, in her investigations, a number of different response systems were monitored and the critical findings centered on which of these topographically different behaviors occurred to each conditioned stimulus.

As in earlier work by Ricci (1973) and Newlin and LoLordo (1976), we found that the absolute fre- quency of responding to CS2 was generally less than that to CS1. However, the bearing of this fact on the issue of CS2-CS1 association remains uncertain. There is, of course, no logical necessity for CS2-CS1 association formation to take place during serial conditioning. In the absence of CS2-CS1 association, CS1 could control more responding than CS2 merely because it occurs closer in time to US delivery than CS2 and, hence, it is more excitatory. Conversely, the same response differential might arise because CS2 occurs more distant in time 
from reinforcement than CS1 and, hence, it is more inhibitory. And, even granting the possibility of CS2-CS1 association, it is not altogether certain that one should expect CS1 responding to exceed CS2 responding; perhaps, if the animal anticipates both CS1 and the US, it should respond more to CS2 than to CS1 (CS2 has two sources of excitation, CS1 has only one).

Although we have emphasized the fact that our methods isolate the association of conditioned stimu$\mathrm{li}$, it is clear that these associations would never have been manifested were it not for the fact that food delivery followed CS2-CS1 pairings. With our procedures, food presentation is necessary for producing keypecking. The question of whether food presentation is also necessary for association formation between CS2 and CS1 is not answered by the present experiments (see Browne, 1976, and Zentall \& Hogan, 1975, for evidence pertinent to this question with first-order conditioning procedures). Nor is the equally interesting question of whether the associations formed involve sensory-sensory or sensorymotor neural connections (see Rashotte, Griffin, \& Sisk, 1977, and Rescorla, 1973, 1977, for data bearing on this question). We hope that our methods will be as helpful in elucidating these issues as they were in producing reliable CS-CS conditioning effects.

And finally, the present results indicate that not only are associations between conditioned stimuli rapidly formed, but also that when formed, these associations are quite stable and persistent. This contrasts markedly with the results of earlier studies in which the assessment of association formation took place under conditions not involving biologically significant stimulation. Characterizations of associations between biologically insignificant or conditioned stimuli as weak and unstable (Asratyan, 1965) should certainly be reconsidered in light of our results and those of others (especially Rescorla, 1973, 1977).

\section{REFERENCES}

Asratyan, E. A. Compensatory adaptations, reflex activity, and the brain. Oxford: Pergamon Press, 1965.

Browne, M. P. The role of primary reinforcement and overt movements in autoshaping in the pigeon. Animal Learning $\&$ Behavior, 1976, 4, 287-292.

Mackintosh, N. J. The psychology of animal learning. London: Academic Press, 1974.
Newlin, R. J., \& Lolordo, V. M. A comparison of pecking generated by serial, delay, and trace autoshaping procedures. Journal of the Experimental Analysis of Behavior, 1976, 25, 227-241.

Rashotte, M. E., Griffin, R. W., \& Sisk, C. L. Second-order conditioning on the pigeon's keypeck. Animal Learning \& Behavior, 1977, 5, 25-38.

Razran, G. Mind in evolution: An East-West synthesis of learned behavior and cognition. Boston: Houghton-Mifflin. 1971.

Rescorla, R. A. Second-order conditioning: Implications for theories of learning. In F. J. McGuigan \& D. B. Lumsden (Eds.), Contemporary approaches to conditioning and learning. Washington, D.C: Winston, 1973. Pp. 127-150.

Rescorla, R. A. Pavlovian second-order conditioning: Some implications for instrumental behavior. In $\mathrm{H}$. Davis \& H. M. B. Hurwitz (Eds.), Operant-Pavlovian interactions. Hillsdale, N.J: Erlbaum, 1977. Pp. 133-164.

RiccI, J. A. Key pecking under response-independent food presentation after long simple and compound stimuli. Journal of the Experimental Analysis of Behavior, 1973, 19. 509-516.

Rudenko, L. P. On the functional structure of conditioned reflexes to serial stimuli in dogs. Acta Neurobiologiae Experimentalis, 1974, 34, 69-79.

SEIDEL R. J. A review of sensory preconditioning. Psychological Bulletin, 1959, 56, 58-73.

Sutherland, N. S., \& Mackintosh, N. J. Mechanisms of animal discrimination learning. New York: Academic Press, 1971.

Tномpson, R. F. Sensory preconditioning. In R. F. Thompson \& J. F. Voss (Eds.), Topics in learning and performance. New York: Academic Press, 1972. Pp. 105-129.

Wasserman, E. A. The effect of redundant contextual stimuli on autoshaping the pigeon's keypeck. Animal Learning \& Behavior, 1973, 1, 198-206

Wasserman, E. A. Stimulus-reinforcer predictiveness and selective discrimination learning in pigeons. Journal of Experimental Psychology, 1974, 103, 284-297.

Wasserman, E. A., \& Anderson, P. A. Differential autoshaping to common and distinctive elements of positive and negative discriminative stimuli. Joumal of the Experimental Analysis of Behavior, 1974, 22, 491-496.

Wasserman, E. A., Franklin, S. R., \& Hearst, E. Pavlovian appetitive contingencies and approach versus withdrawal to conditioned stimuli in pigeons. Journal of Comparative and Physiological Psychology, 1974, 86, 616-627.

Wasserman, E. A., \& McCracken, S. B. The disruption of autoshaped key pecking in the pigeon by food-tray illumination. Journal of the Experimental Analysis of Behavior, 1974, 22. 39-45.

Wickens, D. D. Classical conditioning, as it contributes to the analyses of some basic psychological processes. In F. J. McGuigan \& D. B. Lumsden (Eds.), Contemporary approaches to conditioning and learning. Washington, D.C: Winston, 1973. Pp. 213-243.

Zentall, T. R., \& Hogan, D. E. Key pecking in pigeons produced by pairing keylight with inaccessible grain. Journal of the Experimental Analysis of Behavior, 1975, 23, 199-206.

(Received for publication July 8, 1977; revision accepted September 7, 1977.) 